\title{
Adoption Factors of m-Commerce in Jordan: From Personal and Societal Norms Perspectives
}

\author{
Ghassan Alnajjar, M. Mahmuddin, and T. Ramayah
}

\begin{abstract}
Davis in the Technology Acceptance Model (TAM) distinguished the importance of subjective norms. However, Davis observed the difficulty to distinguish between the users own attitude and the referents on one's intent by others. This has formed a need for further research to investigate the phenomenon of subjective norms and to identify the key antecedents that determine subjective norms. As m-commerce gains popularity, further examination of how subjective norms affect individual attitude might help contribute to the greater usage. This paper, therefore, contributes in decomposing subjective norms (SN) into four norms: personal injunctive norm (PIN), personal descriptive norm (PDN), societal injunctive norm (SIN) and societal descriptive norm (SDN). The aim of this paper is to decompose $\mathrm{SN}$ and to distinct the antecedents of $\mathrm{SN}$. The initial results of 412 university students in Jordan indicate that personal injunctive norm, personal descriptive norm and the societal injunctive norm are indeed antecedents of SN.
\end{abstract}

Index Terms-Attitude, m-commerce adoption, subjective norms, technology acceptance model.

\section{INTRODUCTION}

The proliferation and the emerging of mobile phones in a wireless networks' have made m-commerce a phenomenon and a vital technology. Apparently, m-commerce gain more benefits than e-commerce as consumers can access $\mathrm{m}$-commerce services anytime anywhere with no restriction to a physical terminal. However, practically, m-commerce is still undersized in spite of its availability and high growth numbers of mobile phone users in rising. The future of $\mathrm{m}$-commerce relies on customers' rate of adoption and usage. $\mathrm{M}$-commerce is defined as the use of mobile devices such as mobile phones, personal digital assistant (PDA) to conduct any direct or indirect transaction over the wireless telecommunication networks [1].

The growth trends of the two technologies of mobile telecommunication and the wireless internet have made it possible for m-commerce to gain popularity in some countries such as Japan which it exceeded $\$ 10$ billion market in 2009 [2]. Moreover, according to the same source [2] $\mathrm{m}$-commerce will grow to be $\$ 119$ billion by 2015 .

M-commerce acceptance rate is varies in different cultures. Arab countries and Jordan in specific are a collectivist culture. Social norms score higher in collectivist cultures and these social norms can play a major role in adopting or rejecting a new technology [3]. Predicting individuals' intention to

Manuscript received June 18, 2012; revised July 15, 2012.

G. Alnajjar and M. Mahmuddin are with the School of Computing at the Universiti Utara Malaysia, Sintok Malaysia. (e-mail: Ghassan313@yahoo.com).

T. Ramayah is with the College of Management at the Universiti Sains Malaysia, P. Penang, Malaysia. adopt m-commerce in a collectivist culture, low individualism and high uncertainty avoidance comparing to western society is worthy of investigating. Thus, decomposing social norms is highly valued in collectivist cultures.

The purpose of this paper is to examine the antecedents of subjective norms. To better, understand adoption factors of $\mathrm{m}$-commerce. The rest of the paper is organized as follows: section two provides information about the technology acceptance model (TAM) and brief literature review, and then section three presents study framework and research hypotheses. Next, data collection is discussed, followed by and finally discussion of the results was concluded.

\section{LITERATURE REVIEW}

TAM is the most popular model used to predict and explain the behavioral intention in IT. Reference [4] introduced the TAM to study the usage and behavioral intention based on the theoretical foundation of psychological model of the Theory of Reasoned Action (TRA). Davis confirmed that causal linkages between belief-attitude-intention-behavior which can predict and explain the user's acceptance of a technology. In order to predict usage, the behavioral intention is determined by attitude that, in turn, is influenced by two beliefs: perceived usefulness and perceived ease of use [4]. Davis referred to perceived usefulness as the degree to which the end-user believes that using the system will enhance the performance [4]. Whereas, on the other hand, perceived ease of use referred to the degree to which the end-user believes that using the system will be free of effort. According to [4], perceived usefulness and perceived ease of use are the "fundamental determinants" of predicting the end-user technology acceptance. In summary, TAM includes four factors to predict system usages: perceived usefulness, perceived ease of use, attitude, and behavioral intention.

There has been some strength for TAM. First, according to [5], TAM has become a well-established, powerful and parsimonious model for explaining and predicting information systems end-user acceptance. TAM has been used in a number of technology contexts, like electronic banking [6], and electronic commerce [7]. The second strength is that TAM consider less general than TRA [4]. On the other hand, SN is not accounted in TAM. Reference [8] investigated extended TAM model in related to the adoption of smart phone application. They stated that, "We have to conclude that the role of social norms requires further examination" (pp. 252).

Subjective norm is defined as the social pressure on the users to adopt or not to adopt a technology. TRA, Theory of 
Planned Behavior (TPB), and Decomposed TPB (DTPB) have proven the significance of subjective norm toward behavioral intention. Existing $\mathrm{m}$-commerce studies found conflicted results regarding the influence of $\mathrm{SN}$ toward behavioral intention. Reference [4]-[8]-[9] found no significant influence of SN toward behavioral intention. However, [5]-[10]-[12] found a significant relationship between $\mathrm{SN}$ and behavioral intention.

According to [10], a monolithic SN cannot represent multidimensional factors. Therefore, [10], decomposed SN into peers influence and superiors influence, others researchers decomposed SN into family, spouse and friends. In this paper, drawing from the human communication research field, we demonstrate the possibility of incorporating [13] decomposing of $\mathrm{SN}$ into information systems (IS) research by using PIN, PDN, SIN and SDN factors in the context of $\mathrm{m}$-commerce.

Therefore, in this study, we decomposed SN into personal injunctive norm, personal descriptive norm, societal injunctive norm and societal descriptive norm. According to [3], injunctive norm refers to as others approved or disapproved the behavior whereas descriptive norm refers to as others performed the behavior. SN can be divided into two levels: personal and societal levels. Reference [13] defined personal injunctive norm as 'individuals' belief regarding approval or disapproval of the behavior in question by those valued others" (p.196) such as family and friends. Whereas, personal descriptive norm as "individuals' beliefs regarding the popularity of the behavior in question among those who are important to the respondent or whose opinion the respondent values" (p.196). On the societal level, the authors stated, "regarding societal-level perceived norms, individuals can differ in their beliefs regarding the popularity and approval level of the behavior in question in their society" (p.196). According to [14], societal norm refers to "adhering to the larger societal fashion (large circle of influence)" (pp. 244).

\section{FRAMEWORK AND HYPOTHESES}

Fig. 1 illustrates the research model for the study. TAM presents the theoretical framework for this research. The extension derived from TRA of SN. The paper focuses on the effects of SN on attitude (the original TAM factors are not tested in this paper). This extension attempts to examine and understand the antecedents of SN from personal and societal levels. We proposed five hypotheses over the model:

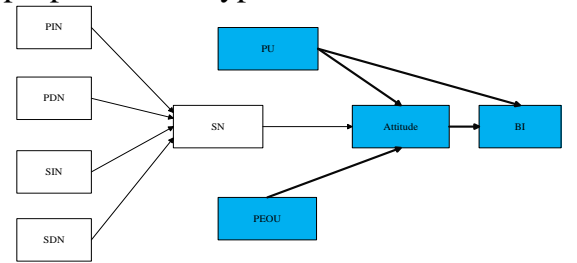

Fig. 1. Research model (blue boxes are the original TAM factors)

Attitude in TRA, TAM and TPB can be either positive or negative. The more favorable (positive) the attitude, the stronger should be an individual's behavioral intention to perform (adopt) the behavior. Previous studies [3]-[4] have found that attitude significantly influenced behavioral intention and has a direct positive relationship toward behavioral intention.

Reference [15] suggested that the individual's perception is influenced by social environment, which means the people who are important to him/her think he/she should approve or disapprove the behavior. Reference [16] stated that "People's attitudes, behavior, and perceptions are affected by the information he or she receives from the social environment" (p.361). Therefore, we propose the following hypothesis:

\section{H1: SN positively influences attitude}

In this study, we feel that $\mathrm{SN}$ is an important factor in a collectivist culture like Jordan. According to [17], Arab countries are a collectivist culture. Social norms are highly valued in collectivist cultures and these social norms can play a major role in adopting or rejecting a new technology [3]. Due to the importance of $\mathrm{SN}$, the decomposition is necessary. Reference [3] conducted a study examining the factors to use internet stock trading in Malaysia. Findings support that descriptive norm and injunctive norms are antecedents of SN. Reference [13] stated "there are actual levels of descriptive and injunctive norms among a certain group and in their society, individuals can vary in their perception of those norms that exist at both the personal and the societal level"(p.196). This paper for the first time is investigating personal descriptive norm, personal injunctive norm, societal descriptive norm, and societal injunctive norm in $\mathrm{m}$-commerce domain. Therefore, we propose the following hypotheses:

\section{H2: PIN positively influences $S N$ \\ H3: PDN positively influences $S N$ \\ H4: SIN positively influences $S N$ \\ H5: SDN positively influences $S N$}

\section{DATA COLlECtion}

A survey questionnaire was employed to gather data using 7-point Likert scale. The scale ranges from (1) "strong disagree to (7) "strong agree" with (4) as "neutral". The questionnaire contains two parts. The first part is mainly the demographics information. The second part contains the main questionnaire. The participants were university students selected from public and private universities in Jordan. Students were screened to ensure they were mobile phone users. It really does not matter which mobile operator and mobile services are used as long as the participants are mobile phone users. A total of 448 responses were obtained from 500 questionnaires. From the 448, 36 were discarded due to missing or incomplete data. The collected data were analyzed using the SPSS 17 software.

\section{RESUlts}

The age distribution of the participants is predominantly between 18 and 26 (92.5 percent). The gender distributions of the participants are (60.4 percent) males and (39.6 percent) are females. Most of the participants are undergraduate students (88 percent). Majority of participants (86.9 percent) are using prepaid scheme. About (92.5 percent) of the participants are internet users more than one year. Although (73.1 percent) of the participants are aware of m-commerce, only (20.1 percent) are m-commerce users. 
Table I shows the descriptive statistics for the constructs, number of items and Cronbach Alphas. All Cronbach Alphas values are greater than 0.70 , which indicate that the instrument has internal consistency.

The research hypotheses were tested by linear and multiple regression analysis. All hypotheses were supported except H5, which was found to be insignificant. Table 2 shows the results of hypotheses testing.

Subjective norm was positively associated with attitude. Finally, personal injunctive norm, personal descriptive norm and societal injunctive norm have a significant effect on subjective norm. Societal descriptive norm was found to have an insignificant effect on subjective norm.

\section{DISCUSSION OF RESEARCH HYPOTHESES}

Results research model explains the constructs that are influencing subjective norm and attitude to predict m-commerce adoption in Jordan. The following conclusions were drawn from the model.

The findings support the research hypothesis (H1: SN $\rightarrow$ Attitude). Existing m-commerce literature supports the relationship in line with studies conducted by [18], and [16]. Prospective adopters of $\mathrm{m}$-commerce are exposed to social influences. These social influences are associated with user's attitude when the prospective adopters are uncertain about $\mathrm{m}$-commerce services before making a choice (adopt or reject) [16].

\begin{tabular}{lllll}
\multicolumn{5}{c}{ TABLE I: DESCRIPTIVE STATISTICS AND RELIABILITY } \\
\hline \hline Construct & Mean & S.D & $\begin{array}{l}\text { N. of } \\
\text { Items }\end{array}$ & $\begin{array}{l}\text { Cronbach's } \\
\text { Alpha }\end{array}$ \\
\hline Attitude & 4.64 & 1.19 & 3 & 0.770 \\
SN & 4.29 & 1.08 & 5 & 0.823 \\
PIN & 4.56 & 1.12 & 3 & 0.844 \\
PDN & 4.07 & 1.23 & 3 & 0.847 \\
SIN & 4.30 & 1.21 & 3 & 0.867 \\
SDN & 3.96 & 1.25 & 3 & 0.866 \\
\hline \hline
\end{tabular}

TABLE II: RESEARCH HYPOTHESES RESULTS

\begin{tabular}{lllll}
\hline \hline & $\begin{array}{l}\text { Research } \\
\text { Hypothesis }\end{array}$ & $\begin{array}{c}\text { St. } \\
\text { Coefficients } \\
\text { Beta }\end{array}$ & $\begin{array}{l}\text { Sig. } \\
\text { Level }\end{array}$ & Support \\
\hline H1 & SN $\rightarrow$ Attitude & 0.365 & 0.000 & Yes \\
H2 & PIN $\rightarrow$ SN & 0.162 & 0.000 & Yes \\
H3 & PDN $\rightarrow$ SN & 0.337 & 0.000 & Yes \\
H4 & SIN $\rightarrow$ SN & 0.111 & 0.032 & Yes \\
H5 & SDN $\rightarrow$ SN & 0.018 & 0.734 & No \\
\hline \hline
\end{tabular}

The hypotheses $(\mathrm{H} 2: \mathrm{PIN} \rightarrow \mathrm{SN}),(\mathrm{H} 3: \mathrm{PDN} \rightarrow \mathrm{SN})$ and $(\mathrm{H} 4:$ $\mathrm{SIN} \rightarrow \mathrm{SN})$ are supported by the results of this research. Presenting confirmation that personal injunctive and descriptive norm and the societal injunctive norms are indeed antecedents of subjective norms. This result was expected. According to [3], social norms score higher in collectivist cultures and these social norms can play a major role in adopting $\mathrm{m}$-commerce.

The hypothesis (H5: $\mathrm{SDN} \rightarrow \mathrm{SN}$ ) is not supported by the results of this study. This may be explained by the fact that when individuals decide to adopt m-commerce in Jordan, they perceive others think they should do, not necessarily what they believe others are doing.

\section{CONCLUSION}

The main objectives of this research are decomposing and distinguishing the antecedents of subjective norms on two levels (personal and societal). Evidently, the study found that personal injunctive norm, personal descriptive norm and the societal injunctive norm are antecedents of subjective norms. This study tested the connection between the SN and attitude to adopt $\mathrm{m}$-commerce in Jordan, rather than the usages of $\mathrm{m}$-commerce. Future study should use a longitudinal point of view into the association between $\mathrm{SN}$-attitude-intention and the usage.

\section{REFERENCES}

[1] J. H. Wu and S. C. Wang, "What drives mobile commerce? An empirical evaluation of the revised technology acceptance model," Inf. Manage., vol. 42, pp. 719-729, 2005.

[2] P. Robles. (2010). [Online]. Available: http://www.econsultancy.com/blog/5435-mobile-commerce-to-grow-t o-119bn-by-2015-report.

[3] T. Ramayah, K. Rouibah, M. Gopi, and G. J. Rangel, “A decomposed theory of reasoned action to explain intention to use Internet stock trading among Malaysian investors," Computers in Human Behavior vol. 25, pp. 1222-1230, 2009.

[4] F. D. Davis, "Perceived usefulness, perceived ease of use, and user acceptance of information technology," MIS Quarterly, vol. 13, pp. 319-340, 1989

[5] V. Venkatesh and F. D. Davis, "A Theoretical Extension of the Technology Acceptance Model: Four Longitudinal Field Studies," Manage. Sci., vol. 46, pp. 186-204, 2000.

[6] K. Rouibah, R. Thurasamy, and O. S. May, "User Acceptance of Internet Banking In Malaysia: Test of Three Competing Models," International Journal of E-Adoption (IJEA), vol. 1, pp. 1-19, 2009.

[7] A. Eckhardt, S. Laumer, and T. Weitzel, "Who influences whom Analyzing workplace referents social influence on IT adoption and non-adoption," Journal of Information Technology, vol. 24, pp. 11-24, 2009.

[8] H. Verkasalo, C. López-Nicolás, F. J. Molina-Castillo, and H. Bouwman, "Analysis of users and non-users of smartphone applications," Telematics and Informatics, vol. 27, pp. 242-255, 2010.

[9] M. Khalifa and K. N. Shen, "Explaining the adoption of transactional B2C mobile commerce," Journal of Enterprise Information Management, vol. 21, pp. 110-124, 2008.

[10] S. Taylor and P. A. Todd, "Understanding Information Technology Usage: A Test of Competing Models," Information Systems Research, vol. 6, pp. 144-176, June 1, 1995

[11] T. T. Wei, G. Marthandan, A. Y. L. Chong, K. B. Ooi, and S. Arumugam, "What drives Malaysian m-commerce adoption? An empirical analysis," Industrial Management \& Data Systems, vol. 109, pp. 370-388, 2009.

[12] H. Nysveen, P. Pedersen, and H. Thorbjørnsen, "Intentions to use mobile services: Antecedents and cross-service comparisons," Journal of the Academy of Marketing Science, vol. 33, pp. 330-346, 2005.

[13] H. S. Park and S. W. Smith, "Distinctiveness and Influence of Subjective Norms, Personal Descriptive and Injunctive Norms, and Societal Descriptive and Injunctive Norms on Behavioral Intent: A Case of Two Behaviors Critical to Organ Donation," Human Communication Research, vol. 33, pp. 194-218, 2007.

[14] P. A. Pavlou and L. Chai, "What Drives Electronic Commerce across Cultures? Across-Cultural Empirical Investigation of the Theory of Planned Behavior," J. Electron. Commerce Res., vol. 3, pp. 240-253, 2002.

[15] M. Fishbein and I. Ajzen, "Belief, attitude, intention, and behavior: An introduction to theory and research," Reading, MA: Addison-Wesley, 1975.

[16] C. López-Nicolás, F. J. Molina-Castillo, and H. Bouwman, “An assessment of advanced mobile services acceptance: Contributions from TAM and diffusion theory models," Information \& Management, vol. 45, pp. 359-364, 2008

[17] G. Hofstede (2009). Geert Hofstede's Cultural Dimensions. [Online]. Available: http://www.clearlycultural.com/geert-hofstede-cultural-dimensions/

[18] W. Zhiping, "Exploring Consumer Attitude on Mobile Commerce From Aspect of Three Roles of MC Adopters," presented at the Proceedings of the 2009 Eighth International Conference on Mobile Business, 2009. 